J. Lake Sci. (湖泊科学) , 2013, 25(4): 471-477

http: //www.jlakes.org. E-mail : jlakes@niglas.ac.cn

(C) 2013 by Journal of Lake Sciences

\title{
淀山湖底泥生态疏浚适宜深度判定分析”
}

何 伟 ${ }^{1,2,3}$, 商景阁 ${ }^{1,3}$, 周麒麟 ${ }^{1,3}$, 程南宁 ${ }^{2}$,范成新 ${ }^{1 * *}$

(1: 中国科学院南京地理与湖泊研究所湖泊与环境国家重点实验室,南京 210008)

(2: 上海勘测设计研究院, 上海 200434)

(3: 中国科学院大学, 北京 100049)

摘 要: 通过室内模拟实验, 对淀山湖东部湖区的沉积物进行研究, 测定沉积物在不同疏浚深度和疏浚温度下的铵态氮 $\left(\mathrm{NH}_{4}^{+}-\mathrm{N}\right)$ 、正磷酸盐 $\left(\mathrm{PO}_{4}^{3-}-\mathrm{P}\right)$ 和溶解性有机碳 ( DOC) 的释放速率, 并对该区域沉积物的理化指标进行检测. 结果表明: 淀山湖表层沉积物近年来总磷和有机质含量有较大增加. 淀山湖东部湖区 $\mathrm{NH}_{4}^{+}-\mathrm{N}$ 和 DOC 存在着释放趋势, $\mathrm{PO}_{4}^{3-}-\mathrm{P}$ 在夏 季会从沉积物中向上覆水中释放,在年内会形成“源”和“汇”的转化. 整个淀山湖东部湖区按不同研究区域划分,疏浚深 度以 $10 \sim 20 \mathrm{~cm}$ 最佳, 疏浚季节以秋季为佳. 通过对淀山湖东部湖区的沉积物在不同疏浚深度和疏浚时间下的污染物释 放速率的研究, 可以为淀山湖和其它类似湖泊的疏浚工作提供相应的科学依据.

关键词: 底泥疏浚;释放速率; 疏浚深度;疏浚温度;淀山湖

\section{Determination of appropriate-ecological sediment dredging depth in Lake Dianshan, China}

HE Wei ${ }^{1,2,3}$, SHANG Jingge ${ }^{1,3}$, ZHOU Qilin ${ }^{1,3}$, CHENG Nanning ${ }^{2}$ \& FAN Chengxin ${ }^{1}$

(1: State Key Laboratory of Lake Science and Environment, Nanjing Institute of Geography and Limnology, Chinese Academy of Sciences, Nanjing 210008, P. R. China)

(2: Shanghai Investigation, Design and Research Institute, Shanghai 200434, P. R. China)

(3: University of Chinese Academy of Sciences, Beijing 100049, P. R. China)

Abstract:Based on the simulated experiment in laboratory, physicochemical characteristics of sediment in eastern Lake Dianshan were measured, and release rates of ammonia, orthophosphate and dissolved organic carbon were measured under different simulated dredging depths and temperatures. The results were shown as follow : total phosphate and organic matter in surface layer of sediment increased several times during recent years in the eastern Lake Dianshan. The release flux direction of ammonia and dissolved organic carbon were from sediment to water column in the whole year, comparing to the reverse release flux direction of orthophosphate, except in summer. The role of sediment in phosphate cycle changed between "pool" and "source" in different seasons. The best dredging depth was $10-20 \mathrm{~cm}$ in the research area, and the best dredging season was autumn. The results provide information for the decision of dredging parameters in the practice of dredging project.

Keywords: Sediment dredging; release rates; dredging depth; dredging temperature; Lake Dianshan

浅水湖泊的内源污染是影响湖泊生态功能和富营养化程度的重要因素之一 ${ }^{[1-2]}$,国内外许多湖泊在外 源污染得到有效控制的情况下,湖泊水质在一定时期内仍没有得到明显的改善,内源污染负荷成为阻碍浅 水湖泊水质提高的一个重要原因 ${ }^{[2-3]}$.

目前国内外对湖泊内源污染的治理主要包括生态疏浚、覆盖等工程手段 ${ }^{[4-7]}$.生态疏浚通过绞吸的方式 将污染物质含量较高的表层沉积物移除,可以提高水质、改善水生生态环境,以达到控制湖泊内源污染的目

* 中国科学院知识创新工程重要方向性项目 (KZCX2-EW-314)、江苏省产学研项目 (BY2011165) 和中国科学院南京 地理与湖泊研究所科研启动项目 (NIGLAS2011QD09) 联合资助. 2012-11-13 收稿; 2013-02-05 收修改稿. 何伟,男,1985 年生,博士研究生;E-mail : hewei1022@ gmail. com.

** 通信作者;E-mail : cxfan@ niglas. ac. cn. 
的. 生态疏浚目前在我国被广泛地应用于浅水湖泊的内源治理中 ${ }^{[7-8]}$, 与传统的航道维护、水库扩容等工程 疏浚不同,生态疏浚旨在清除污染底泥, 改善水体环境, 因此疏浚深度成为了生态疏浚效果保证的一个重要 工程参数 ${ }^{[9-10]}$, 疏浚深度过浅, 富含污染物的表层沉积物没有得到充分去除, 仍会持续影响水质和生态环境 改善; 疏浚深度过深, 不仅工程造价和施工难度加大, 同时也不利于湖泊综合整治方案, 影响后期的生态恢 复. 此外疏浚工程实施时的环境温度也会给疏浚效果带来一定的差异, 但是目前并没有统一的生态疏浚标 准, 在疏浚深度确定等问题上缺乏精确可靠的技术 ${ }^{[8]}$.

目前疏浚深度确定的方法主要有分析沉积物营养物质垂向剖面浓度的 “拐点法” ${ }^{[11-12]}$, 依据吸附热力学 的 “吸附/解析法” ${ }^{[9]}$ 等. 但是这些方法仅对沉积物本身性质进行研究探讨, 没有考虑到疏浚这一工程措施对 沉积物扰动后的实际变化过程, 在疏浚工程实施后, 新生沉积物一水界面在上覆水和沉积物的共同作用下会 发生一系列物理、化学和生物的变化 ${ }^{[1]}$, 这就需要对疏浚这一工程手段来进行模拟, 探讨新生界面处所发生 的营养盐物质通量的大小和方向变化问题. 同时, 每个湖泊都有其独特的沉积物分布特征和污染历史, 因此 针对每个具体湖泊来确定底泥疏浚深度等相关问题就显得格外重要 ${ }^{[13]}$. 本文通过对淀山湖拟疏浚的东部湖 区的调查, 利用室内模拟疏浚方法, 对表层沉积物不同深度和不同温度下的营养盐释放通量进行研究, 试图 为以后类似区域的疏浚工作提供相应的科学依据.

\section{1 材料与方法}

\section{1 研究点概况}

淀山湖位于江苏省和上海市交界处, 是上海市唯一的淡水湖泊,也是黄浦江重要的水源地之一. 湖泊面 积 $62 \mathrm{~km}^{2}$, 平均水深 $2.11 \mathrm{~m}$, 最大水深 $3.59 \mathrm{~m}$, 平均水温 $20.6^{\circ} \mathrm{C}^{[14-15]}$. 近年来由于受到上游地区工农业、旅

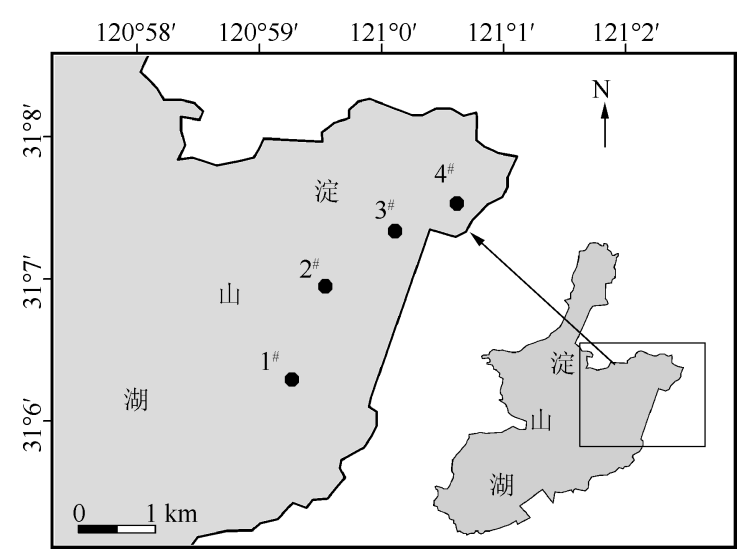

图 1 淀山湖沉积物采样点位置

Fig. 1 Location of sediment sampling sites in Lake Dianshan 游业的发展和渔业养殖的影响, 淀山湖水质不 断下降,综合水质标准由过去的 II 类为主下降 为目前的 IV $\sim \mathrm{V}$ 类, 淀山湖已经逐渐转化为重 度富营养化湖泊 ${ }^{[16-17]}$, 因此上海市加大了对淀 山湖的治理力度, 综合利用各种治理手段来提 高和改善淀山湖地区水环境问题.

在上述一系列的治理手段中, 就包括了部分 区域的生态疏浚,其中拟在淀山湖东部湖区进行 疏浚, 因此本次研究在拟疏浚的淀山湖东部湖区 选取了 4 个样点, 通过对样点不同条件下污染 物质释放速率进行研究, 探讨该区域的合理疏 浚深度. 淀山湖东部湖区采样点由南向北均匀 布设, 其中 $1^{\#} 、 2^{\#}$ 点与上海市水上运动场平行设 置, 相距岸边较远, $3^{\#} 、 4^{\#}$ 点靠近岸边 (图 1), 沉 积物差异较大,因此两者之间的间距较小.

\section{2 样品的采集与处理}

于 2011 年 10 月, 利用沉积物柱状采样器 (直径 $90 \mathrm{~mm}$, 长 $500 \mathrm{~mm}$ ) 进行沉积物样品的采集, 根据各个样 点实际沉积物性状采集不同深度的柱状样品, 样品沉积物一水界面上覆盖原位上覆水, 保持采样过程中沉积 物一水界面不被扰动, 柱状样两端用橡胶塞子密封. 每个采样点采集 4 根沉积物柱状样, 其中 3 根用于分析不 同温度、不同疏浚深度下沉积物营养盐的释放, 1 根用于分析沉积物的基本理化性质. 采集的沉积物柱状样 长度在 $20 \sim 30 \mathrm{~cm}$ 之间, 沉积物表层有 $5 \sim 10 \mathrm{~cm}$ 呈现浅黄色的流泥层, 在流泥层下是 $10 \mathrm{~cm}$ 左右的淤泥层, 呈现黑灰色, 有明显的臭味, 在淤泥层下则是灰色的营养盐含量较小的沉积物层. 利用采水器在各点位采集 湖水,用浮游植物网进行过滤, 滤去藻类的湖水用于室内静态释放实验.

\section{3 实验方法及模拟条件控制}

目前国内外的环保疏浚精度多控制在 $10 \mathrm{~cm}$ 以内 ${ }^{[18-19]}$, 因此本研究以 $10 \mathrm{~cm}$ 为间隔, 对研究区域中采集 
的样品进行不同疏浚深度的静态释放实验. 根据研究区域历史上不同季节的水温状况, 实验控制温度分为 冬季温度组 $\left(5^{\circ} \mathrm{C}\right)$, 春、秋季温度组 $\left(15^{\circ} \mathrm{C}\right)$, 夏季温度组 $\left(25^{\circ} \mathrm{C}\right)^{[20]}$.

根据 4 个样点的实际采集沉积物柱状样深度, 4 个点位模拟疏浚后静态释放实验的样品深度分别为: $1^{\#}$ 点位分为 $0 \mathrm{~cm}$ (没有模拟疏浚) 、 $10 \mathrm{~cm} 2$ 层, $2^{\#}$ 点位分为 $0 、 10 、 20 \mathrm{~cm} 3$ 层, $3^{\#}$ 点位分为 $0 、 10 、 20 \mathrm{~cm} 3$ 层, $4^{\#}$ 点 位分为 $0 、 10 \mathrm{~cm} 2$ 层.

在静态释放实验中,于室内将柱状样中上层水体用虹吸法抽去, 再用虹吸法沿壁小心滴注已过滤的原 采样点水样,至液面高度距沉积物表面 $20 \sim 30 \mathrm{~cm}$ 处停止,标注刻度.

所有沉积物柱状样均垂直放人恒定温度 $\left(5 、 15 、 25^{\circ} \mathrm{C}\right)$ 的循环水浴恒温器 (Colora WK100, $\pm 0.1^{\circ} \mathrm{C}$ ) 中, 蔽光培养, 水体溶解氧 (DO) 浓度保持在 $8 \sim 9 \mathrm{mg} / \mathrm{L}$ (与现场接近). 即刻取原水样作起始样, 此后在指定时间 用移液管于水柱中段取样,每次取适量体积水样, 同时用过滤的原样点水样补充至水面刻度, 于 $0 、 12 、 24$ 、 $36 、 48 、 72 \mathrm{~h}$ 时进行采样, 水样经 Whatman $\mathrm{GF} / \mathrm{C}$ 滤膜过滤后 $4^{\circ} \mathrm{C}$ 储藏待测. 全部实验至释放速率稳定 $(3 \mathrm{~d})$ 为止.

各物质释放速率的计算基于培养系统中待测物质浓度随时间变化而发生的变化 ${ }^{[21]}$,计算公式为:

$$
F=\left[V\left(c_{n}-c_{0}\right)+\sum_{j=1}^{n} V_{j-1}\left(c_{j-1}-c_{\mathrm{a}}\right)\right] /(S \cdot t)
$$

式中, $F$ 为释放速率 $\left(\mathrm{mg} /\left(\mathrm{m}^{2} \cdot \mathrm{d}\right)\right) ; V$ 为柱中上覆水体积 $(\mathrm{L}) ; c_{n} 、 c_{0} 、 c_{j-1}$ 为第 $n$ 次、0 次 (即初始) 和 $j-1$ 次 采样时某物质浓度 $(\mathrm{mg} / \mathrm{L}) ; c_{\mathrm{a}}$ 为添加水样中的污染物含量 $(\mathrm{mg} / \mathrm{L}) ; V_{j-1}$ 为第 $j-1$ 次采样体积 $(\mathrm{L}) ; S$ 为柱中 水-沉积物接触面积 $\left(\mathrm{m}^{2}\right) ; t$ 为释放时间 $(\mathrm{d})^{[22]}$.

\section{4 样品分析}

静态释放实验过滤后的水样轱态氮 $\left(\mathrm{NH}_{4}^{+}-\mathrm{N}\right)$ 利用纳氏试剂法测定 ${ }^{[23]}$, 正磷 酸盐 $\left(\mathrm{PO}_{4}^{3-}-\mathrm{P}\right)$ 利用钼蓝比色法测定 ${ }^{[24]}$, 溶解态有机碳 (DOC) 利用有机碳分析仪 (Shimadzu, Japan) 测定. 各样点沉积物 按 $5 \mathrm{~cm}$ 间隔分层, 分别测定含水率、孔 隙度、总磷 $(\mathrm{TP})^{[25]}$ 和总氮 $(\mathrm{TN})^{[23]}$ 含 量, 有机质含量以沉积物干样在 $550^{\circ} \mathrm{C}$ 下 灼烧 $6 \mathrm{~h}$ 的烧失量来代替 ${ }^{[26]}$.

\section{2 结果与讨论}

\section{1 沉积物基本理化性质}

淀山湖东部拟疏浚区域各点位的沉 积物含水率在 $30.14 \% \sim 59.70 \%$ 之间, $1^{\#}$ 点位的表层含水率较低, 仅为 $48.24 \%$, $4^{\#}$ 点位的含水率较高, 各层均超过了 $50 \% ; 4^{\#}$ 点表层烧失量最高, 达到 $6.35 \%$, 而 $1^{\#}$ 点的烧失量仅为 $4.26 \%$ (表 1 ).

4 个点位沉积物的 TP 和 TN 含量剖面 特征明显, 含量均随深度增加而下降. $4^{\#}$ 点 位表层沉积物 TP 含量最大,达到 600.80 $\mathrm{mg} / \mathrm{kg}$, 比含量最低的 $2^{*}$ 点位高 69.88 $\mathrm{mg} / \mathrm{kg} ; 3^{\#}$ 点位的表层沉积物 TN 含量最

表 1 各样点沉积物的基本理化性质

Tab. 1 Physicochemical characteristic of each sediment sampling site

\begin{tabular}{ccccccc}
\hline $\begin{array}{c}\text { 样点 } \\
\begin{array}{c}\text { 深度/ } \\
\mathrm{cm}\end{array}\end{array} \begin{array}{c}\text { 含水率/ } \\
\%\end{array}$ & $\begin{array}{c}\text { 孔隙度/ } \\
\%\end{array}$ & $\begin{array}{c}\text { 烧失量/ } \\
\%\end{array}$ & $\begin{array}{c}\mathrm{TP} / \\
(\mathrm{mg} / \mathrm{kg})\end{array}$ & $\begin{array}{c}\mathrm{TN} / \\
(\mathrm{mg} / \mathrm{kg})\end{array}$ \\
\hline $1^{\#}$ & $0 \sim 5$ & 48.24 & 69.97 & 4.26 & 580.12 & 2030.90 \\
& $5 \sim 10$ & 42.10 & 64.51 & 3.99 & 544.03 & 2067.76 \\
& $10 \sim 15$ & 36.04 & 58.48 & 3.66 & 448.02 & 1654.94 \\
& $15 \sim 20$ & 31.25 & 53.19 & 3.51 & 426.04 & 1427.14 \\
$2^{\#}$ & $0 \sim 5$ & 53.03 & 73.84 & 5.19 & 530.92 & 2279.28 \\
& $5 \sim 10$ & 45.41 & 67.52 & 4.77 & 370.24 & 2061.49 \\
& $10 \sim 15$ & 38.46 & 60.98 & 4.72 & 275.84 & 1711.16 \\
& $15 \sim 20$ & 32.54 & 54.67 & 4.82 & 262.38 & 1726.52 \\
& $20 \sim 25$ & 32.56 & 54.69 & 4.68 & 305.25 & 2106.47 \\
& $25 \sim 30$ & 29.13 & 50.68 & 4.60 & 192.26 & 2068.29 \\
$3^{\#}$ & $0 \sim 5$ & 59.70 & 78.74 & 6.17 & 587.80 & 2510.01 \\
& $5 \sim 10$ & 53.18 & 73.95 & 6.07 & 497.17 & 2365.94 \\
& $10 \sim 15$ & 44.89 & 67.07 & 5.57 & 423.57 & 2183.72 \\
& $15 \sim 20$ & 36.19 & 58.64 & 5.06 & 436.10 & 1730.17 \\
& $20 \sim 25$ & 33.87 & 56.15 & 4.94 & 431.17 & 1433.25 \\
& $25 \sim 30$ & 30.14 & 51.89 & 4.48 & 409.61 & 1171.03 \\
$4^{\#}$ & $0 \sim 5$ & 58.94 & 78.21 & 6.35 & 600.80 & 2491.32 \\
& $5 \sim 10$ & 55.23 & 75.51 & 6.10 & 491.81 & 2520.80 \\
& $10 \sim 15$ & 52.13 & 73.14 & 5.10 & 396.84 & 2366.15 \\
& $15 \sim 20$ & 51.26 & 72.45 & 4.31 & 347.25 & 2201.98 \\
\hline
\end{tabular}


区沉积物在过去近 20 年, TP 含量保持稳定, 但是 TN 含量和有机质都有较大幅度的增加, 分别由 $500 \mathrm{mg} / \mathrm{kg}$ 和不到 $1 \%$ 的速率增加数倍 ${ }^{[27]}$, 说明近年来淀山湖流域的工业和人类活动所排放的污染物对淀山湖东部湖 区沉积物造成了明显的影响.

\section{2 沉积物释放速率}

2.2.1 不同疏浚条件对铵氮释放速率的影响 在不同的模拟温度下,淀山湖东部拟疏浚湖区沉积物各点位 的 $\mathrm{NH}_{4}^{+}-\mathrm{N}$ 释放速率均为正值, 即 $\mathrm{NH}_{4}^{+}-\mathrm{N}$ 扩散通量的方向是由沉积物到水体. 随着温度的增加, 各点位 $\mathrm{NH}_{4}^{+}-\mathrm{N}$ 释放速率均呈上升的趋势 (图 2a), 说明温度的增加促进了 $\mathrm{NH}_{4}^{+}-\mathrm{N}$ 释放速率的提高 ${ }^{[28]}$.

$\mathrm{NH}_{4}^{+}-\mathrm{N}$ 的释放速率随着疏浚深度的增加而增大. 这与包先明的实验结果类似 ${ }^{[10]}$, 太湖等浅水湖泊中沉 积物的氧气渗透深度一般为数毫米 ${ }^{[29]}$, 沉积物下部缺氧程度较高, 适宜于反硝化和氨化作用, $\mathrm{NH}_{4}^{+}-\mathrm{N}$ 的含 量远高于表层, 模拟疏浚后下部沉积物直接暴露在上覆水下, 浓度差大, 沉积物中的 $\mathrm{NH}_{4}^{+}-\mathrm{N}$ 会大量扩散到 $\mathrm{NH}_{4}^{+}-\mathrm{N}$ 浓度低的上覆水中, 造成在实验周期内 $\mathrm{NH}_{4}^{+}-\mathrm{N}$ 的释放速率随模拟疏浚深度的增加而增大.

由于室内实验的局限性和原位环境的差异 ${ }^{[30]}$, 本文采取了周期为 $3 \mathrm{~d}$ 的释放模拟实验, 但是从长期来 看, 疏浚后原下部沉积物在直接接触到上覆水之后氧化还原条件发生改变, 可以有效地消减沉积物孔隙水 中 $\mathrm{NH}_{4}^{+}-\mathrm{N}$ 的含量 ${ }^{[10,28]}$.

2.2.2 不同疏浚条件对磷酸盐释放速率的影响 淀山湖东部拟疏浚湖区沉积物柱状样的 $\mathrm{PO}_{4}^{3-}-\mathrm{P}$ 释放方 向基本为负值 (图 2b), $\mathrm{PO}_{4}^{3-}-\mathrm{P}$ 的扩散方向是由水体向沉积物, 说明淀山湖的沉积物是 $\mathrm{PO}_{4}^{3-}-\mathrm{P}$ 的 “汇”, 而不是 “源”. 然而当实验温度为 $25^{\circ} \mathrm{C}$ 模拟夏季淀山湖水环境的时候, $2^{\#}$ 和 $3^{\#}$ 点位的 $\mathrm{PO}_{4}^{3-}-\mathrm{P}$ 释 放速率方向发生了变化, 即发生了由 “汇” 向 “源” 的转化, 这也符合范成新等提出的沉积物在一年的 不同季节中存在着 “源” 和 “汇” 转化的理论 ${ }^{[31]}$. 模拟实验中不同温度下 $\mathrm{PO}_{4}^{3-}-\mathrm{P}$ 的释放速率与钟继承 等的长期模拟疏浚结果相似 ${ }^{[26]}$, 在温度升高的时候, 会导致磷吸附作用的减弱, 说明淀山湖在夏季温 度较高的时候具有由沉积物向水体中释放 $\mathrm{PO}_{4}^{3-}-\mathrm{P}$ 的潜力. 历史资料也表明淀山湖的沉积物存在着 $\mathrm{TP}$ 释放的趋势 ${ }^{[20]}$.

各点位沉积物中 TP 含量均表现为随深度的增加出现明显下降的趋势, 由于人类生产、生活等活动导致 磷负荷的增加, TP 和不稳定磷在表层沉积物, 即新近沉降下的沉积物中含量较高 ${ }^{[21]}$, 因此表层沉积物移除 后,下层沉积物的内源 P 负荷相对较低 (表 1 ).

由于疏浚所新生成的沉积物一水界面与疏浚前相比, 铁磷和钙磷可能均未饱和, 也导致了新生界面暴露 在含氧水体中的时候富含反应成分, 导致磷吸附随着疏浚深度的增加而增加, 例如 $\mathrm{Fe}^{2+}$ 转化为 $\mathrm{Fe}^{3+}$, 形成 $\mathrm{FePO}_{4}$ 沉淀,减少间隙水中的 $\mathrm{PO}_{4}^{3-}-\mathrm{P}$ 含量 ${ }^{[21,32]}$. 因此, 温度的升高会加速沉积物中 $\mathrm{PO}_{4}^{3-}-\mathrm{P}$ 的释放, 而疏浚深 度的增加, 则降低了 $\mathrm{PO}_{4}^{3-}-\mathrm{P}$ 的释放速率. 相关研究也表明 ${ }^{[33]}$, 在浅水湖泊中, 疏浚会减少风浪扰动下的沉积 物再悬浮现象, 夏季和冬季的疏浚均可控制内源磷的释放, 但是在冬季疏浚的效果要比夏季疏浚的效果 显著.

2.2.3 不同疏浚条件对溶解性有机碳释放速率的影响 沉积物中的 DOC 是有机质通过微生物水解和 ( 戻 氧) 发酵等方式溶解成各类具有不同分子量的有机化合物. 已有的研究表明, 沉积物间隙水中的 DOC 含量 显著高于底部上覆水中的 DOC 含量, 导致其向底部水体中扩散 ${ }^{[34]}$.

本次模拟实验中, $2^{\#}$ 样点沉积物的 DOC 释放速率随温度和疏浚深度变化的趋势不明显, 这可能与 $2^{\#}$ 样 点的沉积物柱状样异质性较大有关, 烧失量在 $5 \sim 30 \mathrm{~cm}$ 的深度范围内呈不规则分布, 在 $4.60 \% \sim 4.82 \%$ 间 波动 (表 1). 其它 3 个点位的沉积物 DOC 释放速率方向均为由沉积物向上覆水释放.

各点位在模拟温度为 $15^{\circ} \mathrm{C}$ 时, DOC 释放速率最低, 而 $5^{\circ} \mathrm{C}$ 和 $25^{\circ} \mathrm{C}$ 时, 释放速率明显提高, 其中 $25^{\circ} \mathrm{C}$ 又略 高于 $5^{\circ} \mathrm{C}$ 时的释放速率 (图 2c). 例如在 $3^{\#}$ 点位, $5^{\circ} \mathrm{C}$ 和 $25^{\circ} \mathrm{C}$ 条件下不同疏浚深度的沉积物 DOC 释放速率平 均值为 4.54 和 $87.10 \mathrm{mg} /\left(\mathrm{m}^{2} \cdot \mathrm{d}\right)$, 而 $15^{\circ} \mathrm{C}$ 条件下的 DOC 释放速率平均值只有 $-68.50 \mathrm{mg} /\left(\mathrm{m}^{2} \cdot \mathrm{d}\right)$. 温 度对沉积物 DOC 释放的影响较为复杂, 温度较高时, 微生物的活性增强, 促进有机污染物向上覆水体释 放; 温度较低时, 微生物的活性较低, 但是水体中溶解氧含量提高, 增加氧化还原电位, 加速了有机质的 分解 ${ }^{[35]}$. 


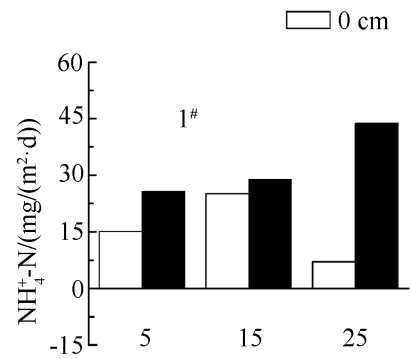

温度 $/{ }^{\circ} \mathrm{C}$
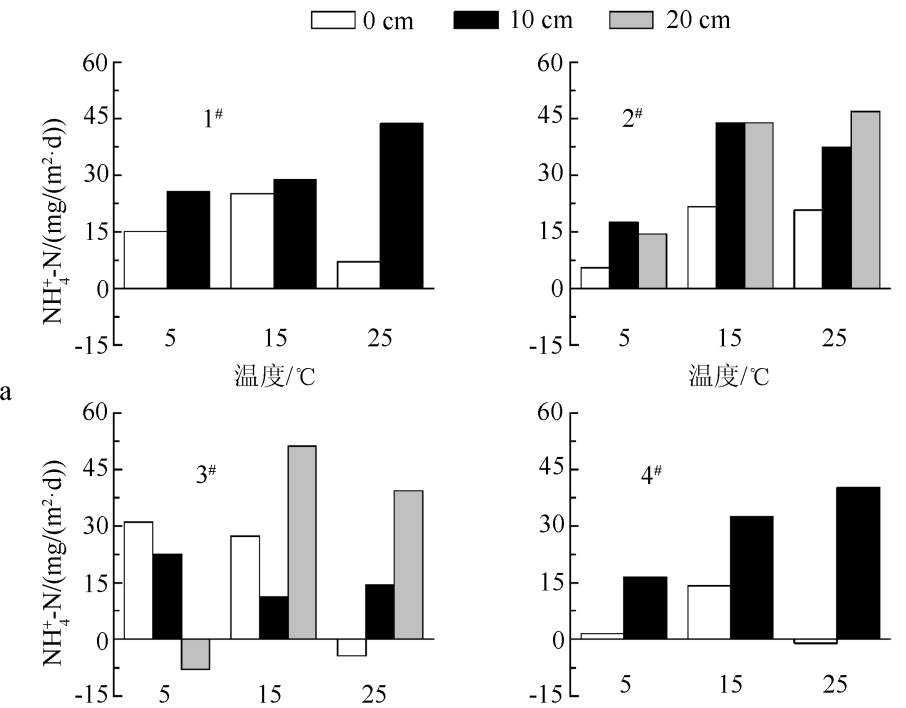

温度 $/{ }^{\circ} \mathrm{C}$
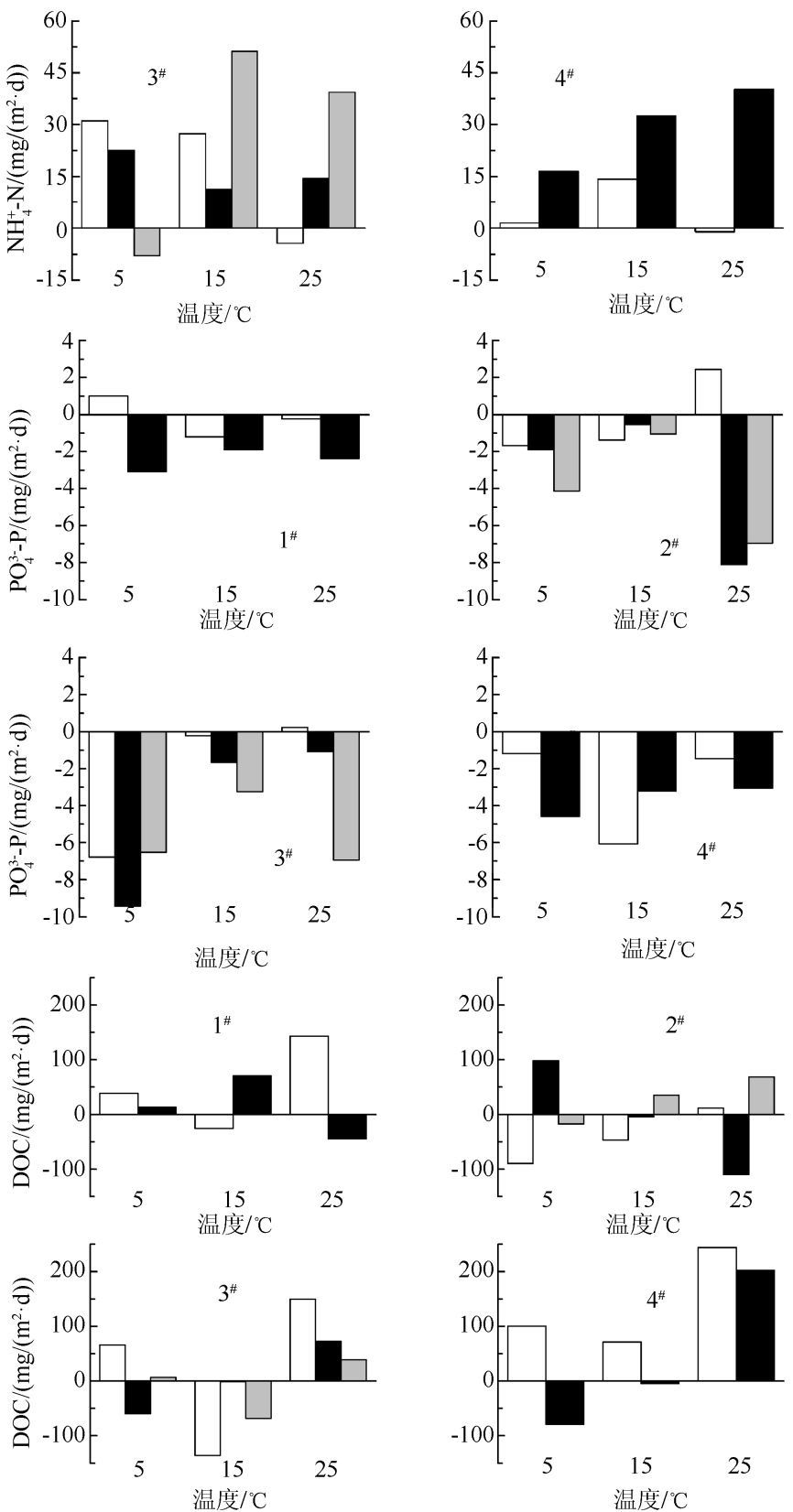

图 2 不同疏浚温度和深度下沉积物 $\mathrm{NH}_{4}^{+}-\mathrm{N}(\mathrm{a}) 、 \mathrm{PO}_{4}^{3-}-\mathrm{P}(\mathrm{b})$ 和 DOC $(\mathrm{c})$ 的释放速率

Fig. $2 \mathrm{NH}_{4}^{+}-\mathrm{N}(\mathrm{a}), \mathrm{PO}_{4}^{3-}-\mathrm{P}(\mathrm{b})$ and $\mathrm{DOC}(\mathrm{c})$ release rates of sediment under different temperatures and depths 
在疏浚深度上, 沉积物 DOC 释放速率呈现出随疏浚深度的增加而减小的趋势, 说明淀山湖拟疏浚区域 近年来受到的人为污染影响较大, 近年来沉降在表层沉积物上的有机质含量较高, 溶解有机碳含量高于下 层沉积物中的含量. 通过疏浚将表层沉积物移除, 可以较好地控制沉积物中 DOC 向水体中扩散的趋势.

\section{3 结论}

1) 利用室内模拟不同疏浚深度, 通过对疏浚后沉积物一水新生界面营养盐物质的静态释放通量研究, 可 以反映疏浚这一工程手段对沉积物进行扰动后的沉积物营养物质释放通量的变化情况, 对疏浚工程中的深 度确定问题有积极和重要的参考意义.

2) 淀山湖东部湖区拟疏浚区域沉积物 $\mathrm{NH}_{4}^{+}-\mathrm{N}$ 处于释放状态, 而 $\mathrm{PO}_{4}^{3-}-\mathrm{P}$ 在温度较高的情况下会由沉积 物中向上覆水释放,在一年内会形成“源”和“汇”的转化.

3) 通过对研究区域内各样点的综合分析, 推荐疏浚深度为: $1^{\#}$ 样点 $10 \mathrm{~cm} 、 2^{\#}$ 样点 $20 \mathrm{~cm} 、 3^{\#}$ 样点 $10 \mathrm{~cm}$ 、 $4^{\#}$ 样点 $10 \mathrm{~cm}, 4^{\#}$ 样点最适疏浚深度要小于泥深. 疏浚深度的确定需要综合考虑目标污染物的垂直分布和释 放速率.

4) 模拟实验中 $5^{\circ} \mathrm{C}$ 条件下沉积物 $\mathrm{NH}_{4}^{+}-\mathrm{N}$ 和 $\mathrm{PO}_{4}^{3-}-\mathrm{P}$ 释放速率最小, $\mathrm{DOC}$ 在 $15^{\circ} \mathrm{C}$ 条件下释放速率最小, 因此推荐在秋季温度较低的时候进行疏浚,疏浚后湖泊水体会有较长时间的低温期,温度也较适宜施工.

致谢: 在样品的采集过程中得到上海勘测设计研究院陆向阳工程师的帮助, 钟继承、余居华等在实验过程中 给予了重要帮助.

\section{4 参考文献}

[1] 钟继承,范成新. 底泥疏浚效果及环境效应研究进展. 湖泊科学, 2007,19(1):1-10.

[ 2 ] Søndergaard M, Jensen JP, Jeppesen E. Role of sediment and internal loading of phosphorus in shallow lakes. Hydrobiologia, 2003, 506-509(1) : 135-145.

[ 3 ] Vanliere L, Gulati RD. Restoration and recovery of shallow eutrophic lake ecosystems in the Netherlands-epilogue. Hydrobiologia, 1992, 233(1/2/3): 283-287.

[ 4 ] Perelo LW. Review : In situ and bioremediation of organic pollutants in aquatic sediments. Journal of Hazardous Materials, $2010, \mathbf{1 7 7}(1 / 2 / 3): 81-89$.

[ 5 ] Ozkundakci D, Duggan IC, Hamilton DP. Does sediment capping have post-application effects on zooplankton and phytoplankton? Hydrobiologia, 2011, $66 \mathbf{6 1}(1)$ : 55-64.

[ 6 ] Gulati RD, van Donk E. Lakes in the Netherlands, their origin, eutrophication and restoration: state-of-the-art review. Hydrobiologia, 2002, 478(1/2/3): 73-106.

[ 7 ] 刘鸿亮,金相灿,荆一风. 湖泊底泥环境疏浚工程技术. 中国工程科学, 1999,1(1):81-84.

[8] 颜昌宙,范成新,杨建华等. 湖泊底泥环保疏浚技术研究展望. 环境污染与防治,2004,26(3):189-192,243.

[9] 王雯雯,姜 霞,王书航等. 太湖竺山湾污染底泥环保疏浚深度的推算. 中国环境科学,2011,31(6):1013-1018.

[10］包先明. 五里湖不同疏浚深度沉积物对氮磷释放的影响. 生态环境, 2007,16(3): 730-734.

[11］姜 霞,王雯雯,王书航等. 笈山湾重金属污染底泥环保疏浚深度的推算. 环境科学, 2012,33(4):1189-1197.

[12] 张润宇, 王立英. 红枫湖后午沉积物磷形态与生物有效磷的垂向分布及疏浚深度推算. 地球与环境, 2012, 40 (4): 554-560.

[13] Gustavson KE, Burton GA, Francingues NR et al. Evaluating the effectiveness of contaminated-sediment dredging. Environmental Science \& Technology, 2008, 42(14) : 5042-5047.

[14] 阮仁良,王 云. 淀山湖水环境质量评价及污染防治研究. 湖泊科学, 1993,5(2):153-158.

[15] 翟建国,徐伯兴. 淀山湖沉积物中硒的存在形态及分布特征. 上海环境科学, 1997,16(9) :18-21.

[16] 哈 欢, 朱宏进, 朱雪生等. 淀山湖富营养化防治与生态修复技术研究. 中国水利, 2009,13:46-48.

[17] 程 䂀, 李小平. 淀山湖氮磷营养物 20 年变化及其藻类增长响应. 湖泊科学, 2008,20(4):409-419.

[18］李金贵,李进军,杨建华等. 污染底泥精确疏浚技术. 中国港湾建设, 2004,133(6): 11-14,20.

[19] 年跃刚,范成新,孔繁翔等. 环保疏浚系列化技术研究与工程示范. 中国水利, 2006,17:40-42,58.

[20］苏丽丹,林卫青, 杨渏帆. 淀山湖底泥氮磷释放通量研究. 上海环境科学, 2010,29(5):197-201. 
[21 ] Reddy KR, Fisher MM, Wang Y et al. Potential effects of sediment dredging on internal phosphorus loading in a shallow, subtropical lake. Lake and Reservoir Management, 2007, 23(1) : 27-38.

[22］范成新,秦伯强,孙 越. 梅梁湖和五里湖水-沉积物界面的物质交换. 湖泊科学,1998,10(1):73-78.

[23] 魏复盛. 水和废水监测分析方法:第 4 版. 北京:中国环境科学出版社,2002:254-257,435-438.

[24] Murphy J, Riley JP. A modified single solution method for determination of phosphate in natural waters. Analytica Chimica Acta, 1962, 26 (1) : 31-36.

[25] Ruban V, Lopez-Sanchez JF, Pardo P et al. Selection and evaluation of sequential extraction procedures for the determination of phosphorus forms in lake sediment. Journal of Environmental Monitoring, 1999, 1(1) : 51-56.

[26] 钟继承,刘国锋,范成新等. 湖泊底泥疏浚环境效应: I . 内源磷释放控制作用. 湖泊科学, 2009,21(1):84-93.

[27] 由文辉. 淀山湖水生维管束植物群落研究. 湖泊科学, 1994,6(4) :317-324.

[28] 钟继承,刘国锋,范成新等. 湖泊底泥疏浚环境效应: II . 内源氮释放控制作用. 湖泊科学, 2009,21(3):335-344.

[29] Zhang L, Shen QS, Hu HY et al. Impacts of Corbicula fluminea on oxygen uptake and nutrient fluxes across the sedimentwater interface. Water Air and Soil Pollution, 2011, 220(1/2/3/4) : 399-411.

[30] Nowlin WH, Evarts JL, Vanni MJ. Release rates and potential fates of nitrogen and phosphorus from sediments in a eutrophic reservoir. Freshwater Biology, 2005, 50(2) : 301-322.

[31] 范成新, 张 路,包先明等. 太湖沉积物一水界面生源要素迁移机制及定量化-2. 磷释放的热力学机制及源一汇 转换. 湖泊科学, $2006, \mathbf{1 8}(3): 207-217$.

[32］高 丽,周健民. 磷在富营养化湖泊沉积物一水界面的循环. 土壤通报,2004,35(4):512-515.

[33] 余居华,钟继承, 张银龙等. 湖泊疏浚对沉积物再悬浮及磷迁移影响的模拟研究. 环境科学, 2012,33 (10): 3368-3375.

[34] 倪建宇, Michael M. 赤道东北太平洋沉积物间隙水中溶解有机碳的分布特征. 海洋学报, 2007,29(1):155-160.

[35] 李雪英, 骆敏聪, 孙省利. 湛江特呈岛红树林区底泥 TOC 的释放研究. 环境科学与技术, 2011,34(1) :34-37. 